\title{
Laboratory Technologist
}

National Cancer Institute

\section{Source}

National Cancer Institute. Laboratory Technologist. NCI Thesaurus. Code C51830.

A technically trained person who performs laboratory activities and provides laboratory analysis according to laboratory policies, procedures and protocols. 